\title{
Comparison of elegance of Japanese and European jackets
}

\author{
KyoungOk Kim ${ }^{1}$, Asako Nozawa ${ }^{2}$, Masayuki Takatera ${ }^{1 *}$ \\ ${ }^{1}$ Division of Kansei and Fashion Engineering, Institute for Fiber Engineering (IFES), Shinshu \\ University, 3-15-1 Tokida, Ueda, Nagano, Japan. \\ ${ }^{2}$ Faculty of Textile Science and Technology, Shinshu University, 3-15-1 Tokida, Ueda, Nagano, \\ Ueda, Japan. \\ Corresponding authors: takatera@ shinshu-u.ac.jp
}

\begin{abstract}
Purpose: This study investigates factors affecting the impression of elegance of a jacket's appearance.

Design/methodology/approach: A questionnaire survey on the impression of jacket appearance was conducted using images of jackets of Japanese and European brands. A paired comparison and sensory test were carried out for four Japanese and European jackets. To explain different jacket appearances, the jacket patterns and silhouettes were investigated from an engineering point of view.

Findings: Most Japanese subjects responded that European jackets in images were more elegant and characteristic of European style. In a comparison of jacket silhouettes, Jacket 1 (European brand) was evaluated as the most elegant. The waist and bust parts of jacket 1 had three-dimensional shape whereas the Japanese jackets had planar and rectilinear shapes. This was due to the difference in the waist darts and curved lines in the patterns. Jacket appearance in terms of elegance is thus mainly affected by the waist and bust shapes, which are affected by darts and lines in the patterns.
\end{abstract}

Originality/value: This is pioneering research on the elegance of garment appearance from an engineering point of view, using actual clothing. The comparison results for commercial jackets will be valuable to the apparel industry.

Keywords: jacket appearance, elegance, image analysis, silhouette analysis, jacket pattern

Paper type: Research paper

\section{Introduction}

Clothing conveys various images or impressions to customers depending on the silhouette, color, handle, drape, body sizing and details. These impressions are important to the selection of clothing by customers (Hines et al., 2007; Solomon et al., 2009). Elegance is usually a target impression of clothing (Wallach et al., 1998; Rashid, 2007). Especially in Japan, elegance is considered an important expression in fashion (The Textile Machinery Society of Japan, 1990). However, Japanese ready-to-wear garments are regarded as less elegant than European garments even when the garments are in the same price range (Akira et al., 2010). Two commercial explanations for this have been given. The first is that the proportion of the administrative cost relative to the design cost is greater in Japan than in Europe (Babazono et al., 2010). The second is that the Japanese and European designs are different for reasons associated with manufacturing and inspection (Ikeda and Otani, 2010). However, there has been no investigation of actual clothing styles and construction.

Appearance, such as the outline or silhouette, is considered as an important factor of clothing impression (Kim et al., 2014). Relationship between size range and styling was mentioned by Brockman (1965). Niwa et al., (1998) investigated silhouette design for ladies' garments based on the mechanical properties of a fabric. It is said that the silhouette and design of Japanese garments differ from those of European garments, especially in terms of elegance. Au et al. (2003) investigated the differences between European and Japanese fashion designers considering their design theory. They showed there are differences social attitude and historical revival in the synthesizing ideas and conducting design evaluation. In terms of the garment pattern, it has been reported that the shape of the armholes in patterns and the seam lines of Japanese garments are different from their European counterparts (Miyatake and Miyazawa, 2012). Clarifying the factors of elegance and the relation of elegance with patterns will help apparel manufacturers design elegant garments.

Several studies have evaluated the visual impression conveyed by clothing. Relations between clothing and its design elements such as color, pattern, texture, and silhouette have been investigated using photographic images (Matsuura et al., 1993). The consistency of preferences for a dress in a photographic image and the relationships between preferences has been studied (Kawamoto et al., 1992). Images of jeans have been evaluated by young and middle-aged people, and the differences reported (Toizumi et al., 1993). Hunt-Johnson et al. investigated the effects of differences in clothing style on 
the impression of sociability (Hunt-Johnson et al., 1977). Chen et al. (2009) investigated images of clothing fabric according to kansei, a Japanese term relating to psychological expression. Ericksen et al. (1992) researched the clothing preferences of employed females taking into account self-image congruence and career anchorage.

For the evaluation of garment appearance, aesthetic evaluation for clothing is carried out by many researchers. Morganosky et al. (1989) investigated the consumers' evaluations of apparel form (which include lines, designs, colors, and shapes ), expression, and aesthetic quality taking into account aesthetic theory, and found that form is more relevant component for aesthetic quality. Chattaraman et al. (2006) investigated the relationship between physical and psychosocial attributes of the body, and aesthetic attribute preferences in clothing. The principle of balance and golden mean for clothing design were mentioned by Brockman (1965). In beauty theory, beauty is related to the form which is connected to the color, line, design, texture, and shape (Clive Bell, 1913). C. H. Stratz investigated the women's beauty through the women's body parts itself and the ratio of each body part (1980). He also discussed the effect of clothing on women's beauty. However, the effects of clothing appearance on the clothing impression of elegance are still unclear. Elegance is an expression which was used for product design including architecture and fashion (Rashid, 2007; Schumacher, 2007). Even though the word 'elegance' is usually used for dresses, nowadays it is used broadly for several kinds of garments, such as jackets, trousers, and skirts. In this study, we investigated the relationship between clothing appearance and the impression of elegance for jackets of Japanese and European brands. To investigate specific aspects of the elegance of the jackets, a questionnaire survey on the impression of elegance of the jackets in photographic images was first conducted. A sensory test and a comparison of jacket silhouettes were then carried out using actual jackets. The patterns of the jackets were also compared.

\section{EXPERIMENTAL}

\section{Questionnaire survey on the impression of jackets in images}

Because the present study was carried out in Japan, Japanese words for 'elegance' were required. Japanese evaluation words corresponding to the 'elegance' of garments were selected by referencing a dictionary (Shoten, 1998) and debating the options among the authors. The opposites of selected words, except the opposites of 'Cool' and 'Cute', were selected. The selected evaluation words are listed in Table 1. The Japanese words are given in parentheses.

Table 1. Evaluation words

\begin{tabular}{|l|l|}
\hline English (Japanese) & English (Japanese) \\
\hline Luxurious (Kökyūna) & Cheap (Yasusōna) \\
\hline Refined (Jyōhinna) & Indecent (Gehinna) \\
\hline Cool (Kakkoii) & Cute (Kawaii) \\
\hline Feminine (Jyoseiteki) & Masculine (Danseiteki) \\
\hline Formal (Fömaruna) & Casual (Kajyuaruna) \\
\hline Seeming to be of Japanese style (Nihonrashii) & $\begin{array}{l}\text { Seeming to be of European style } \\
\text { (Kaigairashii) }\end{array}$ \\
\hline Graceful (Yügana) & Savage (Soyana) \\
\hline Sophisticated (Senrensareta) & Unsophisticated (Yabottai) \\
\hline Complex (Hukuzatsuna) & Simple (Sinpuruna) \\
\hline Three dimensional (Rittaitekina) & Planar (Heimentekina) \\
\hline Mature (Otonappoi) & Childish (Kodomoppoi) \\
\hline
\end{tabular}

To investigate the impression conveyed by jackets, we prepared images of 20 jackets of Japanese and European brands. Tailored jackets for women were selected for the images. The images were obtained from the websites of brands, major shopping sites and collection sites. We divided the jackets into three groups depending on the retail price. The groups are described in Table 2.

The backgrounds of the selected images were removed. Each image was then converted into a black-and-white image to remove the influence of color. We showed the jacket images to subjects in a random order and asked them to select all impression words that described their impression of the jacket in each image among the evaluation words. We scored each word as the number of subjects who selected the word to describe the jacket. The subjects were 18 Japanese university students in their twenties (six males and 12 females) who voluntarily participated. 


\begin{tabular}{|l|l|l|l|}
\hline \multicolumn{1}{|c|}{ Brands } & Price & European brands & Japanese brands \\
\hline Group A & $\begin{array}{l}\text { Prêt-à-porter Winter Collection } \\
\text { (Unknown price) }\end{array}$ & E-A1, E-A2, E-A3, E-A4 & J-A1, J-A2, J-A3 \\
\hline Group B & $\begin{array}{l}\text { from 10,000 JPY (USD 100) to } \\
\text { 35,000 JPY (USD 350) }\end{array}$ & E-B1, E-B2, E-B3 & J-B1, J-B2, J-B3, J-B4 \\
\hline Group C & under 10,000 JPY (USD 100) & E-C1, E-C2, E-C3, E-C4 & J-C1, J-C2 \\
\hline
\end{tabular}

${ }^{*}$ Conversion rate is $100 \mathrm{JPY}=1 \mathrm{USD}$.

\section{Paired comparison of jackets}

To clarify how customers feel a jacket may be elegant, the appearances of four actual jackets were compared in terms of elegance. Preferences for the jacket appearances were also investigated.

Four low-price jackets made by Japanese (Jackets 4 and 3) and European brands (Jackets 1 and 2) were prepared as experimental samples (see Tables 3 and 4). Images of the fronts, sides and backs of the jackets are respectively shown in Figures 1, 2 and 3. Sixteen Japanese university students in their twenties (six males and 10 females) participated in the experiment as volunteers. Scheffe's paired comparison (Nakaya variation) (Scheffe, 1952) was carried out. Subjects evaluated the appearances of nine jacket parts from three directions as shown in Figure 4. Specifically, the subjects evaluated

1) the front, side and back styles of the entire jacket,

2) the bust, collar and lapels, waist and sleeves from the front,

3) the front line and back line from the side, and

4) the shoulders, waist, and sleeves from the back.

The subjects observed actual whole jackets worn on dummies (Kiiya 9AR, bust of $87 \mathrm{~cm}$, waist of $63 \mathrm{~cm}$ and hips of 93 $\mathrm{cm}$ ) from the designated directions and scored the results of a paired comparison on a seven-point scale ranging from more elegant to less elegant for each part of the jacket samples. We selected a dummy to avoid the effect of body differences. The subjects were not informed of the price or the brand of each jacket. We also asked the subject to ignore the fabric type. The test was carried out at a temperature of $20 \pm 1{ }^{\circ} \mathrm{C}$ and relative humidity of $65 \% \pm 5 \%$ under fluorescent lamps.

We also compared and analyzed the silhouettes and patterns of the jackets. The patterns were obtained by dissembling the jackets. The length and the amount of darts (degree of dart in bust) of patterns were also compared.

Table 3 Specifications of the jacket samples

\begin{tabular}{|l|l|l|l|l|l|l|}
\hline Sample & \multicolumn{2}{|l|}{ Manufacturer } & Face fabric & Lining & $\begin{array}{l}\text { Price } \\
\text { (yen) }\end{array}$ & $\begin{array}{l}\text { Country of } \\
\text { production }\end{array}$ \\
\hline Jacket 1 & $\begin{array}{l}\text { European } \\
\text { brands }\end{array}$ & Company Z & $\begin{array}{l}\text { Polyester 49\% } \\
\text { Rayon 49\% } \\
\text { Polyurethane 2\% } \\
\text { (Twill fabric) }\end{array}$ & Acetate 100\% & 8990 & Spain \\
\cline { 1 - 5 } Jacket 2 & Company H & $\begin{array}{l}\text { Cotton 97\% } \\
\text { Polyurethane 3\% } \\
\text { (Satin fabric) }\end{array}$ & Polyester100\% & 5490 & China \\
\cline { 3 - 7 } & \multirow{2}{*}{$\begin{array}{l}\text { Jacket 3 } \\
\text { brands }\end{array}$} & Company W & $\begin{array}{l}\text { Cotton 100\% } \\
\text { (Velvet fabric) }\end{array}$ & Polyester100\% & 15,750 & China \\
\cline { 3 - 7 } & Company U & $\begin{array}{l}\text { Polyester 47\% } \\
\text { Rayon 47\% } \\
\text { Polyurethane 6\% } \\
\text { (Plain fabric) }\end{array}$ & Polyester100\% & 5990 & China \\
\hline
\end{tabular}


Table 4. Sizes of the jacket samples

\begin{tabular}{|l|l|l|l|l|l|}
\hline \multicolumn{2}{|c|}{} & Jacket 1 & Jacket 2 & Jacket 3 & Jacket 4 \\
\hline \multirow{5}{*}{ Measured size (cm) } & Back waist length & 58.5 & 59 & 53.5 & 57 \\
\cline { 2 - 6 } & Shoulder width & 36 & 37 & 37 & 37 \\
\cline { 2 - 6 } & Bust width & 41 & 42 & 44.5 & 42 \\
\cline { 2 - 6 } & Waist width & 37 & 38.5 & 39 & 38.5 \\
\cline { 2 - 6 } & Sleeve length & 61.5 & 61 & 57.5 & 61 \\
\cline { 2 - 6 } & Sleeve width & 15.5 & 15 & 15 & 15 \\
\hline \multirow{5}{*}{ Size on the tag (cm) } & Height & 86 & 84 & 83 & $83-160$ \\
\cline { 2 - 6 } & Bust & 66 & 68 & 63 & $83-69$ \\
\cline { 2 - 6 } & Waist & 94 & 90 & $88-94$ \\
\cline { 2 - 6 } & Hip & & & \\
\hline
\end{tabular}

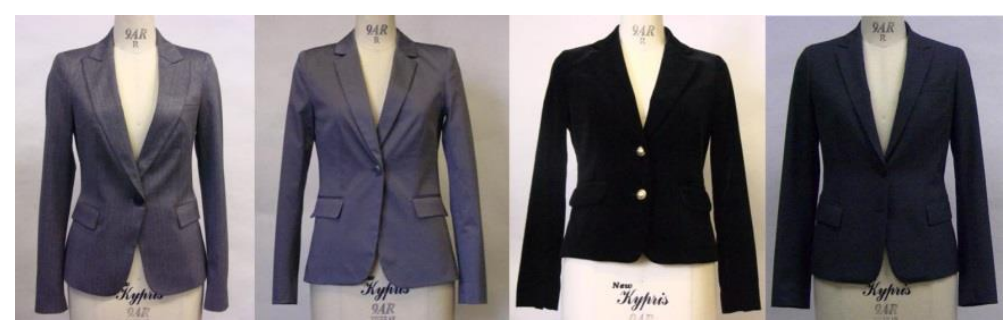
(a) Jacket 1
(b) Jacket 2
(c) Jacket 3
(d) Jacket 4

Figure 1. Images of the fronts of jacket samples.

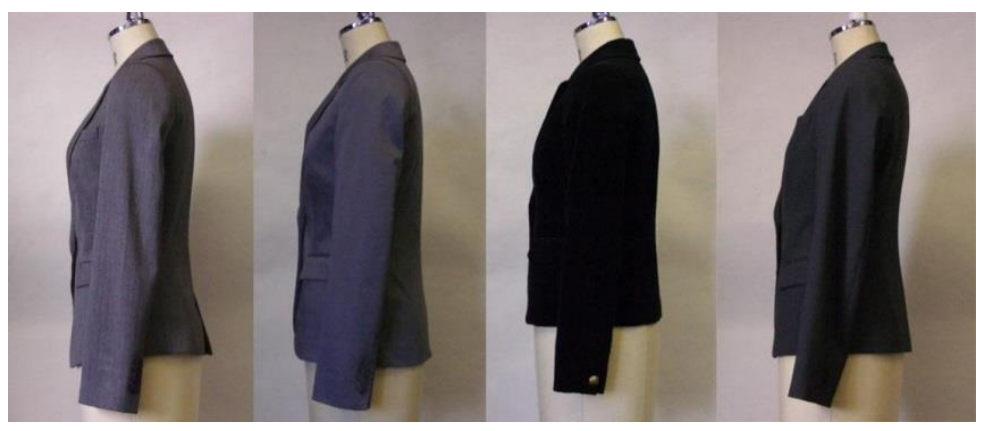
(a) Jacket 1
(b) Jacket 2
(c) Jacket 3
(d) Jacket 4

Figure 2. Images of the sides of jacket samples.

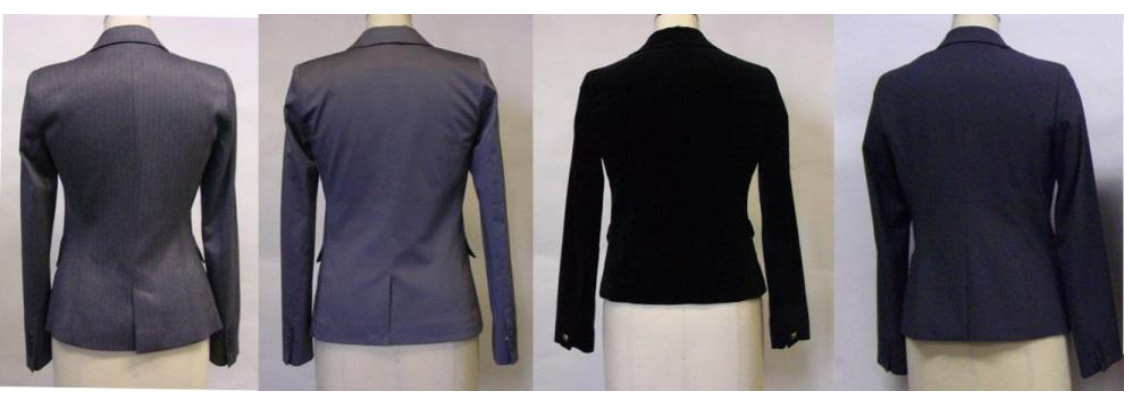
(a) Jacket 1
(b) Jacket 2
(c) Jacket 3
(d) Jacket 4

Figure 3. Images of the backs of jacket samples. 


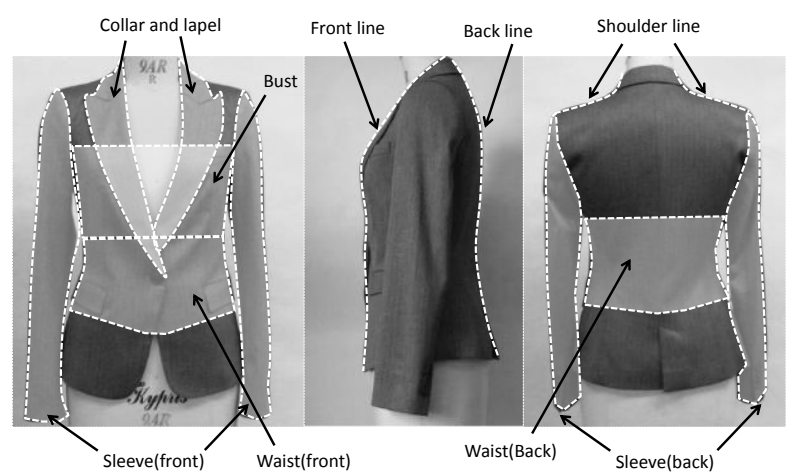

Figure 4. Parts of a jacket referred to in the questionnaire

\section{RESULTS AND DISCUSSION}

\subsection{Questionnaire survey on the impression of jacket images}

The differences between the average scores of European and Japanese jackets for each word are shown in Figure 5. There were large differences (more than 2 points) between jackets of Japanese and European brands for the terms 'Luxurious', 'Refined', 'Seeming to be of European style', 'Cool', 'Seeming to be of Japanese style', 'Casual' and 'Childish'. We therefore mainly investigated the results for these terms. Their opposite words/terms were also considered.

The scores for the items are given in Figures 6-11. In the graphs, samples are sorted by the score of each term. Figure 6 presents the scores of 'Luxurious' and 'Cheap' for the jackets in the images. Almost half of the subjects considered most of the jackets of the European brands as being luxurious and those of Japanese brands as being cheap. The scores of 'Refined' and 'Indecent' for the jackets in the images are shown in Figure 7. Except for E-A4 and E-C3, jackets of European brands were considered as 'Refined', while most jackets of Japanese brands were not. The scores of 'Seeming to be of European style' and 'Seeming to be of Japanese style' for the jackets in the images are shown in Figure 8. Most jackets of European brands were considered as 'Seeming to be of European style'. Most jackets of Japanese brands were considered as 'Seeming to be of Japanese style'. It was thus found that there are obvious differences between the appearances of jacket depending on the country of the brand. The scores of 'Cool' for jackets in the images are shown in Figure 9. Subjects tended to describe the jackets of European brands in the images as 'Cool' more so than for Japanese brands. The scores of 'Formal' and 'Casual' for jackets in the images are shown in Figure 10. The jackets of Japanese brands were considered as 'Casual' while most jackets of European brands were considered as 'Formal'. The scores of 'Mature' and 'Childish' for jackets in the images are shown in Figure 11. The jackets of European brands were described as 'Mature'.

The subjects were thus able to discern the difference between images of jackets of Japanese brands and European brands. Subjects described most jackets of European brands as 'Luxurious', 'Refined', 'Seeming to be of European style', 'Cool', 'Formal' and 'Mature'. Additionally, with the exception of E-C3, images of European jackets in group C, which are of low price, had higher scores for 'Refined' and 'Luxurious'. This reveals that there were common points among the jackets of Japanese brands and common points among the jackets of European brands. The jacket samples conveyed common feelings according to the brand even for a similar price level. Consequently, it was found that subjects felt that jackets of European brands in images were more elegant. To explain this result, we compared four jackets of Japanese and European brands.

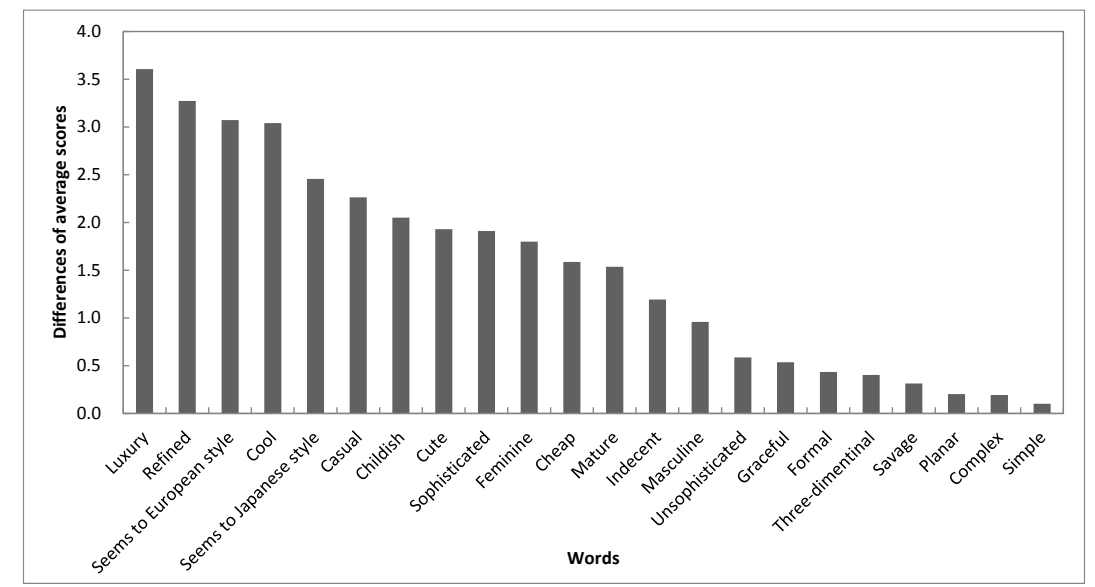

Figure 5. Differences between the average scores for European and Japanese jackets for each word 


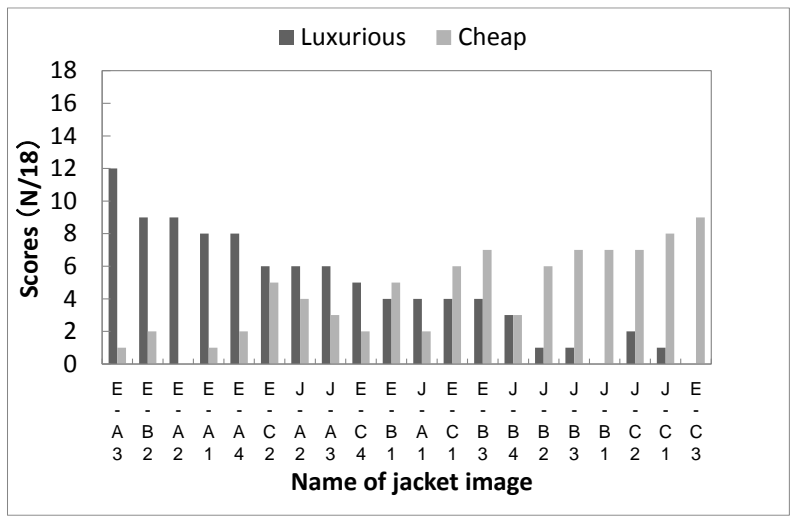

Figure 6. Scores of 'Luxurious' and 'Cheap' for jackets in images.

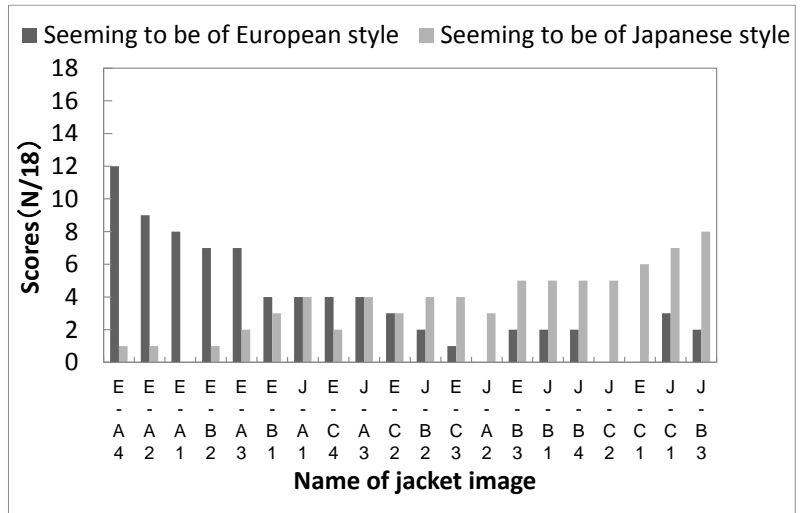

Figure 8. Scores of 'Seeming to be of European style' and 'Seeming to be of Japanese style' for jackets in images.

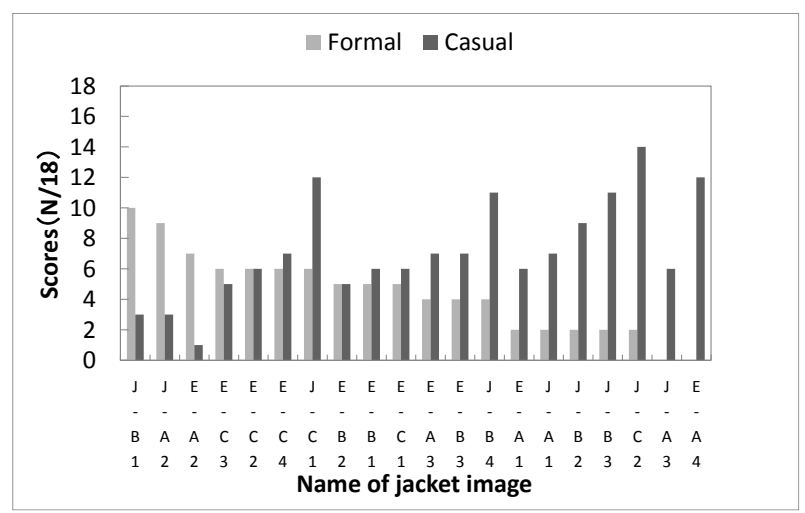

Figure 10. Scores of 'Formal' and 'Casual' for jackets in images.

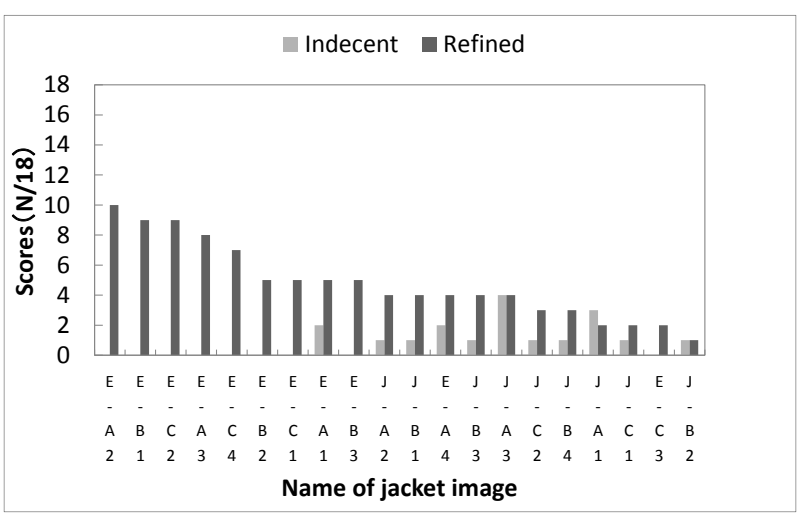

Figure 7. Scores of 'Refined' and 'Indecent' for jackets in images.

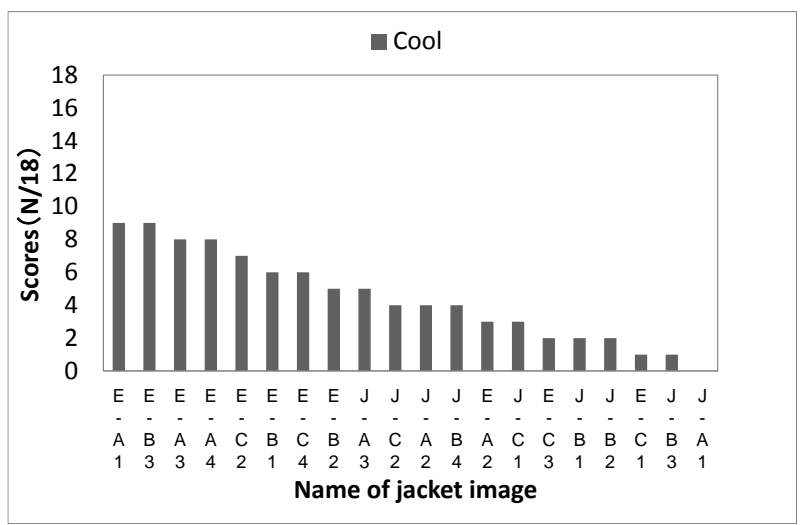

Figure 9. Scores of 'Cool' for jackets in images.

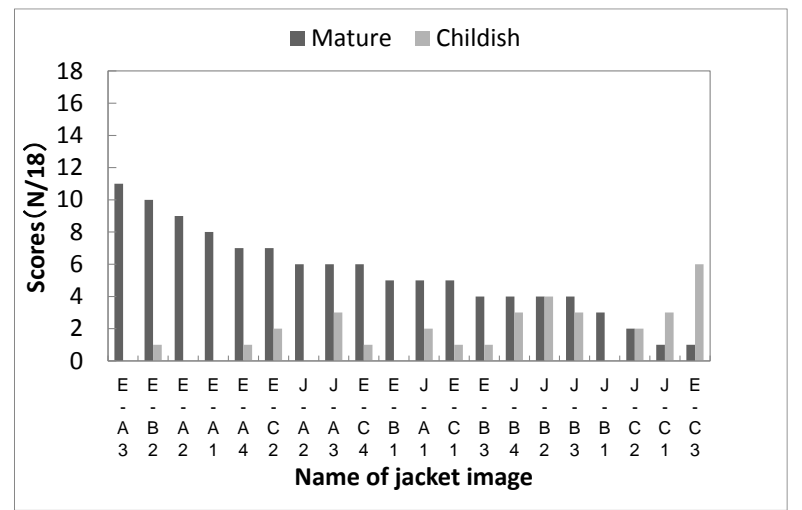

Figure 11. Scores of 'Mature' and 'Childish' for jackets in images.

\subsection{Paired comparison of jackets of Japanese and European brands}

Preference scores obtained in the paired comparison test on the elegance of the appearance of the entire jacket are shown in Figure 12. The significant differences are presented in Figure 13. The figures show that Jacket 1 was highly rated as elegant. The results were close for the other three jackets. The evaluation results for the side and back of Jacket 4 were slightly higher than those for Jackets 2 and 3.

Preference scores on the elegance of the appearance of jacket parts are shown in Figure 14. The significant differences are presented in Figure 15. As for the results for the appearance of the entire jacket, most parts of Jacket 1 rated the 
highest among the jacket samples. The other three jackets had similar results for the parts of the bust, collar and lapels, waist and front line when viewed from the front. However, the values of the three jackets for the shoulder line, waist, sleeve and back line when viewed from the back differed. In particular, values for the back lines of Jackets 1 and 4 when viewed from the side were similar and those of Jackets 2 and 3 were similar. Values for the sleeves viewed from the back were close for all jackets. Values for the sleeves viewed from the front were also close, except in the case of Jacket 2 .

Preference scores on the appearance of jacket samples are shown in Figure 16. The significant differences are presented in Figure 17. Jacket 1 rated the highest, as in the results on the elegance of jackets. Jacket 4 had a higher preference score for jacket appearance than for jacket elegance in Figure 12. However, the preference results for all jackets were very similar to the results for the elegance of the appearance of the entire jacket. It can thus be said that the subjects preferred the elegant appearance of a jacket.

However, that not all jacket parts of European brands were elegant and not all jacket parts of Japanese brands lacked elegance.

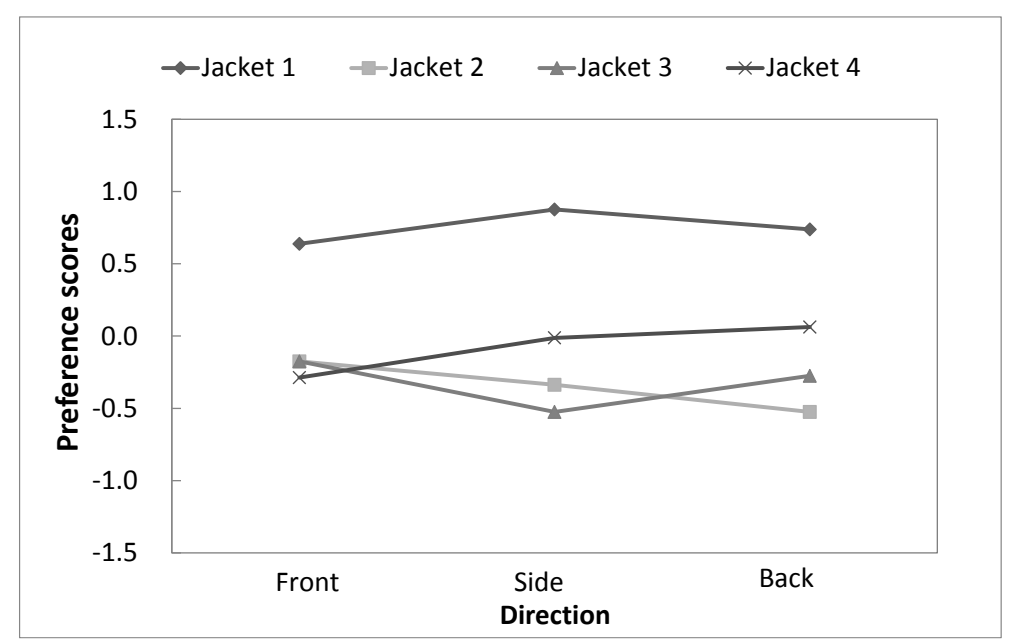

Figure 12. Preference scores on the elegance of the appearance of the entire jacket.

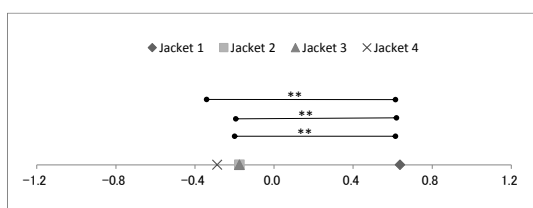

(a) front

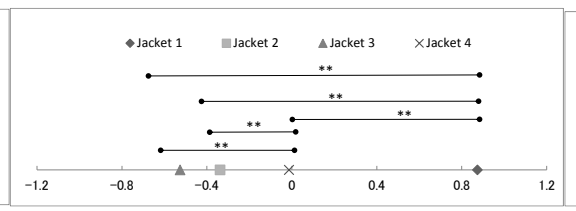

(b) side

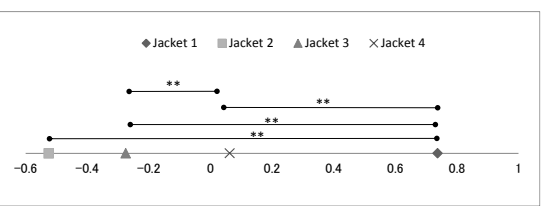

(c) back

Figure 13. Significant differences in the elegance of jackets.

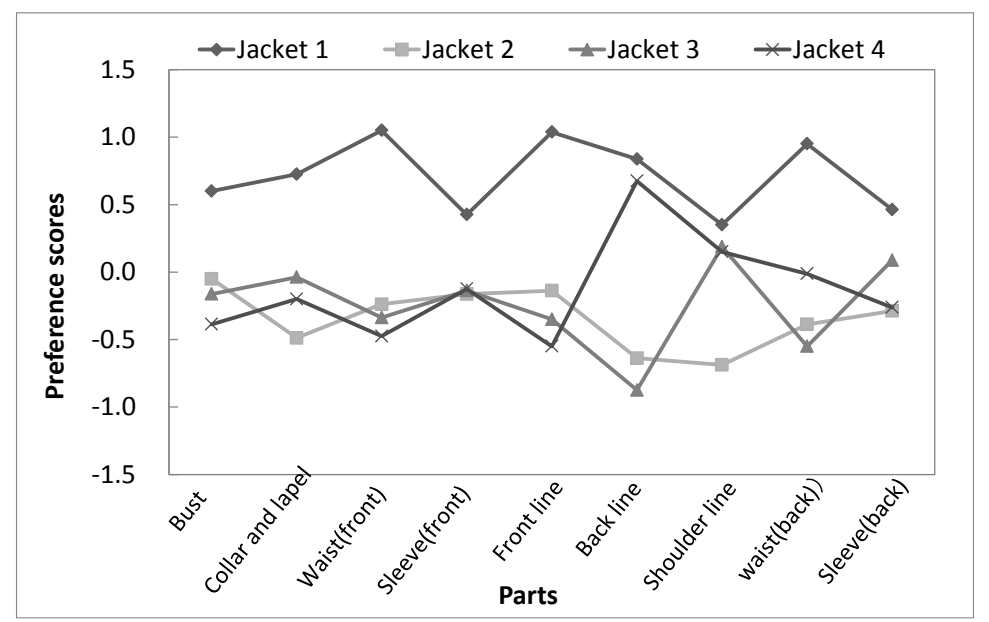

Figure 14. Preference scores on the elegance of the appearance of jacket parts. 


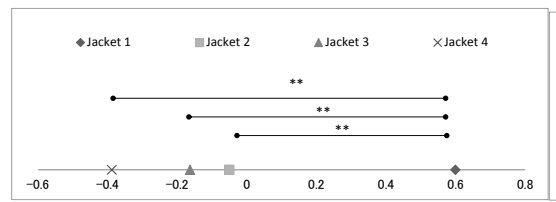

(a) bust

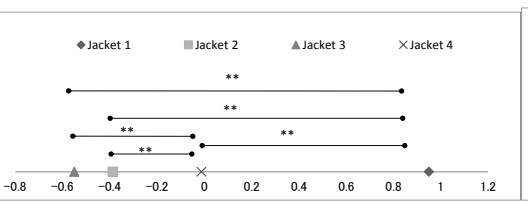

(b) waist (back)

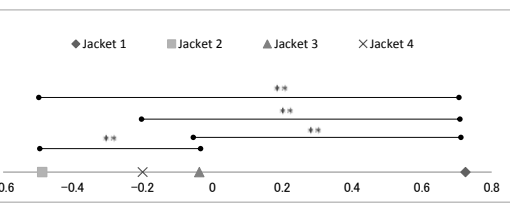

(c) collar and lapels

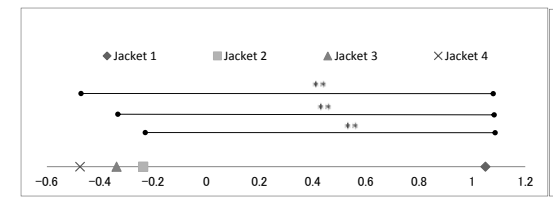

(d) waist (front)

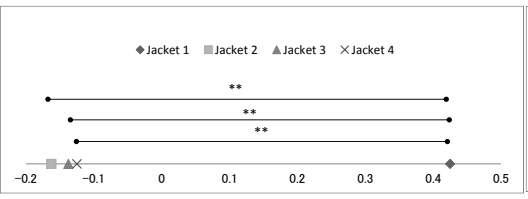

(e) sleeve (front)

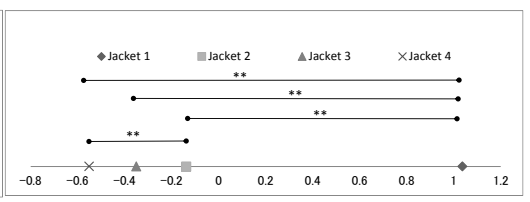

(f) front line

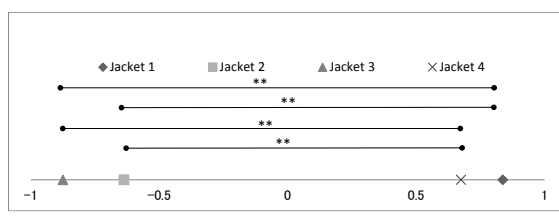

(g) back line

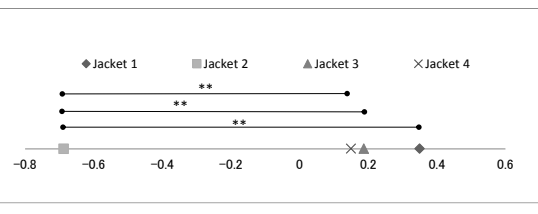

(b) shoulder line

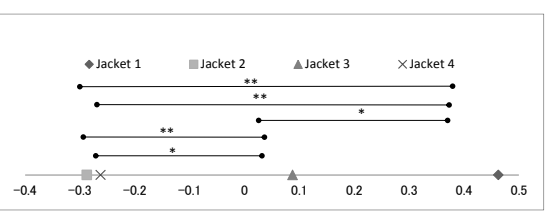

(c) sleeve (back)

Figure 15. Significant differences in the elegance of jacket parts.

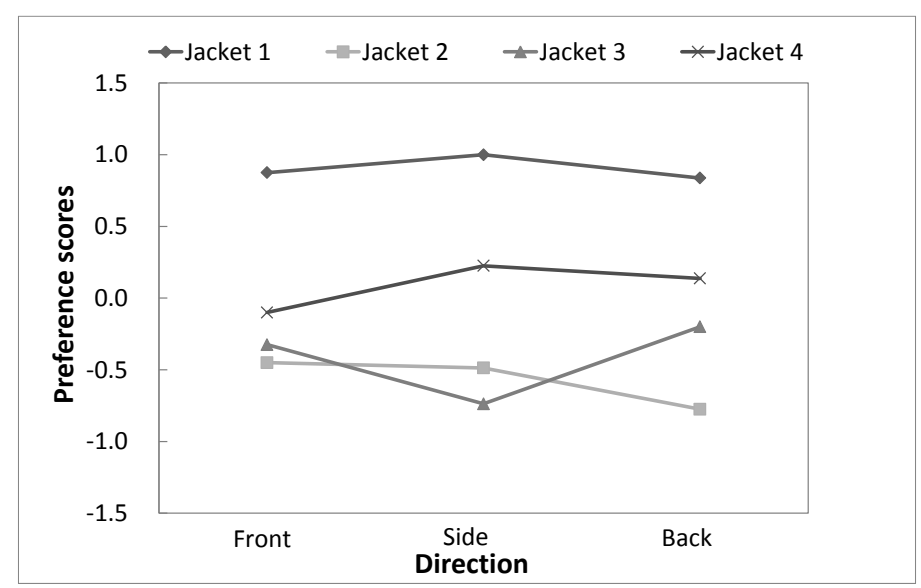

Figure 16. Preference scores on the appearance of jacket samples.

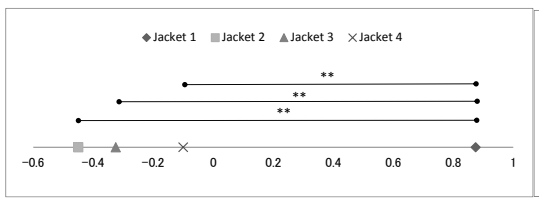

(a) front

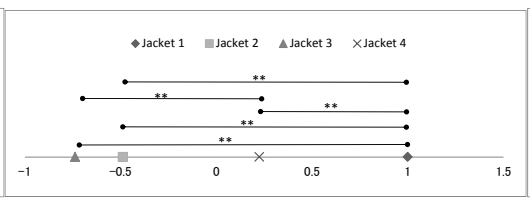

(b) side

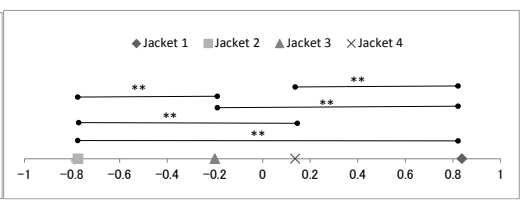

(c) back

Figure 17. Significant differences in the appearance preference of jackets.

The silhouettes and patterns of jacket samples were evaluated in paired comparisons. The patterns obtained from the disassembled jackets are shown in Figure 18.

Jacket 1 had the largest collar and lapels, as shown in Figure 1, and it had the highest preference scores for the collar and lapels in Figure 14. Jacket 1 had the highest preference scores for the bust in Figure 14, and its bust shape was three dimensional whereas the bust shape of Jacket 4 was planar, as shown in Figures 1 and 2. Jacket 1 also had the highest preference scores for the waist as viewed from the front and back; the jacket had a slender and narrow waist shape as shown in Figures 1 and 19. In contrast, Jacket 3 had the lowest preference scores for the waist; it had a steep curved line at the waist and a waist that seemed broader than the waists of the other jackets as shown in Figures 1-3. Table 5 gives the ratios of the waist and bust lengths of the jacket patterns. The ratio of Jacket 1 was the smallest and that of Jacket 3 was the largest.

The constriction of the waist is affected by darts in the patterns. Usually, by controlling the intake and legs of darts in a pattern, a three-dimensional shape and curved line can be generated. The intake and legs of body darts are shown in 
Figure 18. The figure shows that the intake angle of the bust darts were the largest for Jacket 1 and the smallest for Jacket 4 . The number of body panels in a pattern also affects the jacket shape. Jackets 1, 4 and 3 had four body panels and Jacket 2 had three. A high number of panels can readily generate three-dimensional shape. Although Jacket 3 had four panels, it did not have bust or waist darts. This resulted in the steep curve and planar shape of Jacket 3 . Thus, Jacket 1 had a more three-dimensional shape and Jacket 3 had a more planar shape as shown in Figures 1-3. As seen for the bust darts, large darts at the waist make out a strong constriction which was caused by pattern cutting. The waist darts of Jacket 1 were the largest as shown in Figure 18 (a). However, there were no darts in the waist of Jacket 3 as shown in Figure 18 (c).

In the results of comparison, the back lines of Jackets 1 and 4 had higher preference values than those of Jackets 2 and 3 . As shown in Figure 19, the back lines of Jackets 1 and 4 were curved and those of Jackets 2 and 3 were linear. Although most parts of Jacket 1 had higher preference values in the comparison of parts, the values for the shoulder lines of all jackets except Jacket 2 were similar. As shown in Figure 20, the shoulder line, drawn from the neck to the shoulders, of Jacket 2 was linear whereas the shoulder lines of the other three jackets were curved. It is believed that this can be explained by the shoulder pads inserted under the shoulders of the jackets; i.e., Jacket 2 had the thickest shoulder pads.

Table 5. Ratios of the bust to waist of jackets

\begin{tabular}{|l|l|l|l|l|}
\hline Jacket sample & Jacket 1 & Jacket 2 & Jacket 3 & Jacket 4 \\
\hline $\begin{array}{l}\text { Ratio of waist/bust length } \\
\text { of the jacket pattern }\end{array}$ & 0.85 & 0.87 & 0.90 & 0.88 \\
\hline
\end{tabular}

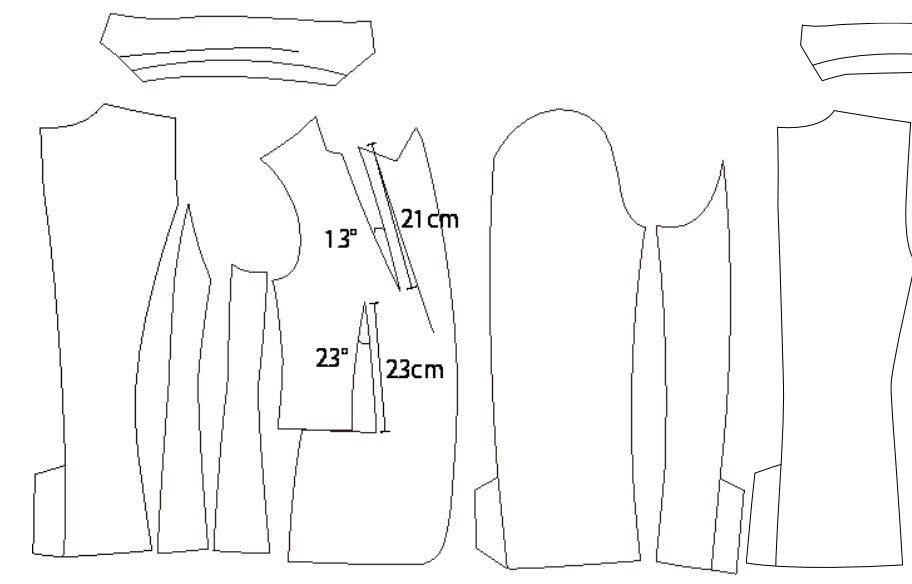

(a) Jacket 1

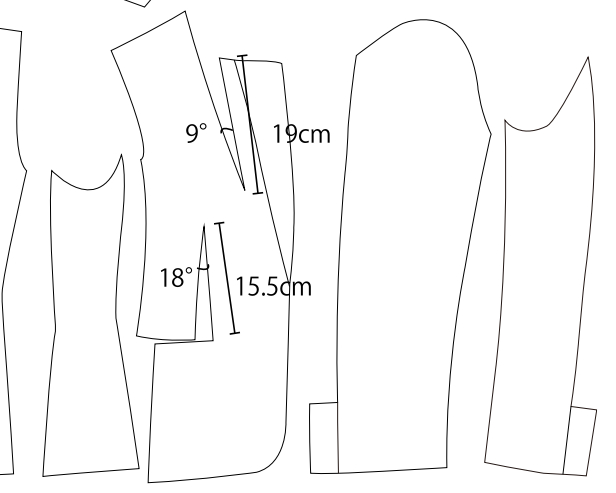

(b) Jacket 2

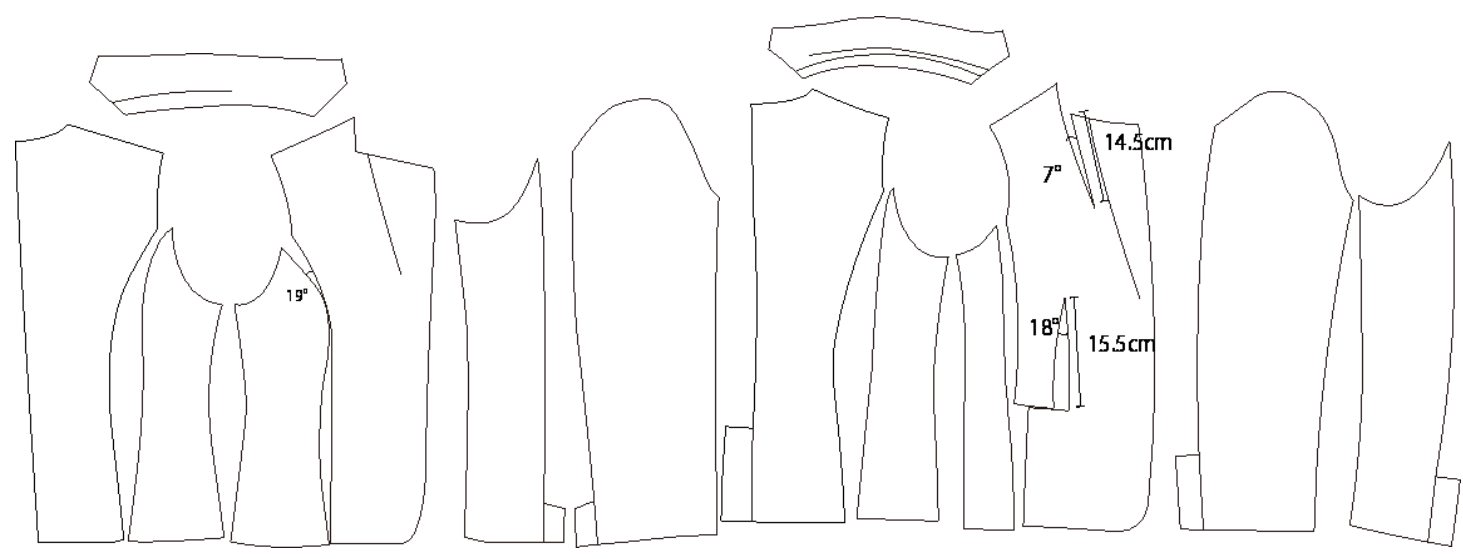

(c) Jacket 3

(d) Jacket 4

Figure 18. Patterns of jacket samples. 


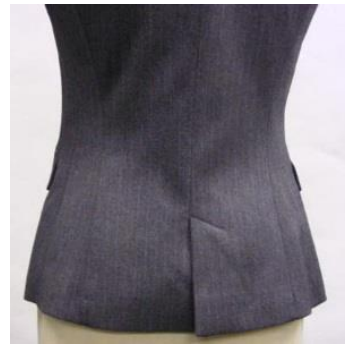

(a) Jacket 1

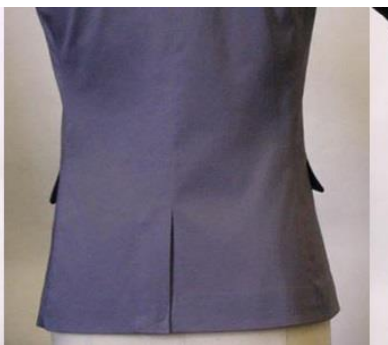

(b) Jacket 2

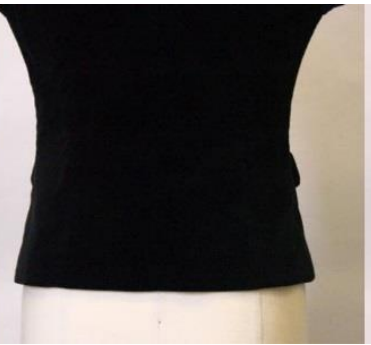

(c) Jacket 3

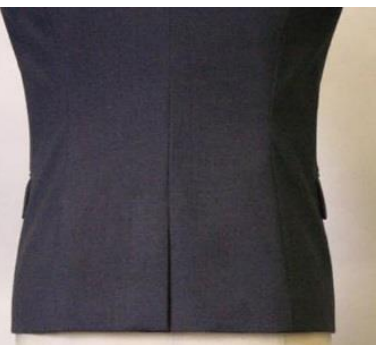

(d) Jacket 4

Figure 19 Waist parts of the jacket samples viewed from the back.

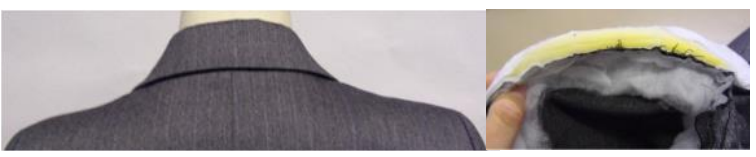

(a) Jacket 1

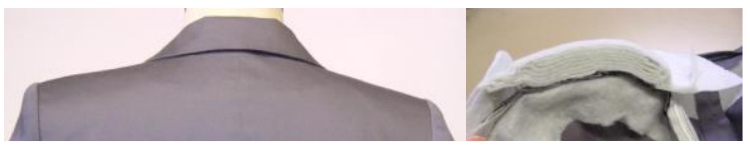

(b) Jacket 2

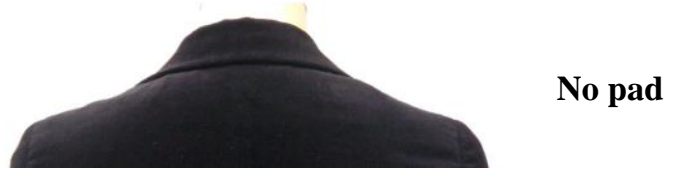

(c) Jacket 3

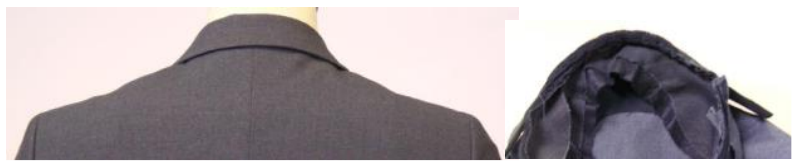

(d) Jacket 4

Figure 20. Shoulder parts of jacket samples.

\section{CONCLUSION}

To clarify the characteristics of elegance, a questionnaire survey and a sensory test were carried out using images and samples of jackets made by Japanese and European brands. The silhouettes and patterns of the jackets were also investigated.

In the evaluation of the impressions conveyed by jackets in images, Japanese subjects discerned a difference in appearance between Japanese and European jackets. Jackets made by European brands were evaluated as being more elegant and 'Seemingly European,' even at the same price level. There was thus a clear difference in the elegance of jacket appearance between jackets made by Japanese and European brands regardless of the price. .

In the comparison of four jackets of Japanese and European brands, European-brand Jacket 1 was evaluated as the most elegant and preferred. The preference values of the appearance of the entire jacket and parts of the jacket were similar except for values for the back line viewed from the side and the sleeves. In particular, the waist, bust and shoulder line of Jacket 1, which provided curved lines and three-dimensional shapes of the waist and bust, were evaluated as being more elegant. It was thus found that curved lines and three-dimensional shapes generate an impression of elegance. Those shapes were affected by the number of panels of the body pattern and the size of darts.

This study on garment design provides garment designers and pattern makers with useful suggestions for manufacturing garments that are more elegant. A further study on other types of garments will help clarify the elegance of garment appearance. Study on the effect of body shape and fabric type will be also necessary in the future study. 


\section{REFERENCES}

Babazono, S., Morikawa, H. and Otani, T. (2010), “The possibility of predicting luxury brand: Lanvin, Balenciaga as examples", in Proc. KEER2010, USB.

Miyatake, K. and Miyazawa, T. (2012), "Product design of Dolce \& Gabbana", Bulletin of the Faculty of Home Economics, Kyoritsu Women's University, Vol. 58, pp. 29-43.

Akira, S. and Otani, T. (2010), “Design and manufacturing process of Maison P in Paris”, Sen’i Torendo, No. 84, pp. 32-39.

Niwa, Masako, et al. (1998), "Optimum silhouette design for ladies' garments based on the mechanical properties of a fabric." Textile research journal, Vol.68 No.8, pp. 578-588.

Au, J., G. Taylor, and E. W. Newton. (2003), "How are European and Japanese Fashion Designers Inspired?." Journal of the Textile Institute Vol. 94, No.1-2, pp. 12-31.

Rashid, Hani. (2007), "Performing Elegance." Architectural Design, Vol. 77, No.1, pp. 76-81.

Schumacher, Patrik. (2007), "Arguing for Elegance." Architectural Design Vol. 77, No.1, pp. 28-37.

Helen Brockman (1965), The Theory of Fashion Design, Wile

C. H. Stratz, Y. Takayama Trans. (1980), The beauty of women (Japanese Edition), 3rd Edition, NISHIDA SHOTEN, Tokyo

Shinmura Izuru ed. (1998), Kojien $5^{\text {th }}$ edtion, Iwanami Shoten, Japan.

Ikeda, K. and Otani, T. (2010), "Experiment on designs and production of Pret-A-Porter that can be sold in Paris and Milano, Production and evaluation of sample for ready-to-wear of Japan and France”, Sen 'i Torendo, No. 85, pp. 35-42.

Bell, C, Significant form, In M. Rader (Ed.), A modern book of esthetics. New York: Holt, Rinehart and Winston.

Matsuura, Y., Man-e, Y., Okita, S., and Nakagawa, S. (1993), "Relation between clothing image and its design part image by canonical correlation analysis”, Sen’i Kikai Gakkaishi, Vol. 46, No. 4, pp. T93-T102.

Kawamoto, E., Watanabe, S., Kuroda, K., Nakazawa, N., and Nakagawa, S. (1992), "Relationship between preference for dress image and clothing behavior", Sen'i Kikai Gakkaishi, Vol. 45, No. 11, pp. T207-T217.

Toizumi, Y., Toda, S., and Nakagawa, S. (1993), “Jeans image and its evaluation”, Sen'i Kikai Gakkaishi, Vol. 46, No. 4, T87-T92.

Kim, K., Miyatake, K., Sano, K., Takatera., M., and Otani, T. (2014), “Comparison of high-end tailored jackets for ready-to-wear produced in Italy and Japan”, International Journal of Affective Engineering, Vol. 13, No. 1, pp. 35-41.

Kim, K., Miyatake, K., Sano, K., Takatera., M., and Otani, T. (2014), "Research on jacket patterns and specifications of ready-to-wear for high-end in Italy and Japan", International Journal of Affective Engineering, Vol. 13, No. 1, pp. $27-33$.

Hunt-Johnson, B., Nagasawa, R.H., and Peters, K. (1977), "Clothing style differences: their effect on the impression of sociability”, Home Economics Research Journal, Vol. 6, No. 1, pp. 58-63.

The Textile Machinery Society of Japan (1990), Social Psychology of Clothing, The Textile Machinery Society of Japan, Osaka, Japan.

Chen, Y.-W., Sobue, S., and Huang, X. (2009), "Kansei based clothing fabric image retrieval, computational color imaging", Lecture Notes in Computer Science, Vol. 5646, pp. 71-80.

Ericksen, M.K. and Sirgy, M.J. (1992), "Employed females' clothing preference, self-image congruence, and career anchorage", Journal of Applied Social Psychology, Vol. 22, No. 5, pp. 408-422.

Michelle A. Morganosky and Deborah S. Postlewait. (1989), “Consumers' Evaluations of Apparel Form, Expression, and Aesthetic Quality", Clothing and Textiles Research Journal, Vol.7, No.2, pp. 11-15

Veena Chattaraman and Nancy Ann Rudd, (2006), "Preferences for Aesthetic Attributes in Clothing as a Function of Body Image, Body Cathexis and Body Size”, Clothing and Textiles Research Journal, No.24, Vol.1, pp. 46-61

Hines, T. and Bruce, M. (2007), Fashion Marketing (second edition), Butterworth-Heinemann, Burlington, MA.

Solomon, M.R. and Rabolt, N.J. (2009), Consumer Behavior in Fashion (second edition), Pearson Education Inc., NJ.

Wallach, J. (1998), Chanel: Her style and Her Life, Nan A. Talese, New York, NY.

Scheffe, H. (1952), “An analysis of variance for paired comparisons”, Jour. Am. Stat. Ass., Vol. 47, pp. 381-400. 